\title{
Strategies for the Promotion of Effective Communication between Teachers and Students
}

\author{
JU Quan-juan \\ Department of Vocational Education, Tianjin University of Technology and Education, Tianjin 300222, P.R. China
}

\begin{abstract}
There are quite a number of communication barriers that exist between teachers and students in the educational fraternity. These communication barriers are as a result of a number of factors and reasons. This paper employs the Case Analysis Method to analyze the communication barriers between teachers and students, and also puts forward effective strategic solutions to the problem of communication breakdown which the teachers need to comprehend and understand. Teachers play a leading role in the process of enhancing communication which in turn help improve on their quality of delivery thereby yielding a positive impact on education. The strategies discussed in this paper include the use of the language model, application of language skills and improved morality. These strategies are lucidly explained in such a way as to help correctly and harmoniously handle students using appropriate means and ways of communication.
\end{abstract}

Keywords: Teacher-student communication, Strategy, Language model

\section{Introduction}

In the teaching process, effective communication between teachers and students is a very important and crucial factor that guarantees good results and is a prerequisite for attaining high quality of education. However, due to a number of individual differences, communication between teachers and students is usually ineffective. Therefore, teachers should adopt scientific, reasonable and advanced action-oriented strategies to actively implement effective communication. People working in the education sector should research and pay much attention to this very important subject. The proper understanding of the communication process in the education system is solely dependent on how teachers and students relate to each other Not until the existing barriers are all resolved, problems and misunderstandings between students and teachers will always be there.

\section{Teacher-Student Communication Barriers}

For the sake of analyzing the communication process, we will consider some typical examples of invalid cases of communication between teachers and students and then find out the barriers to the communication between the two parties involved.

\section{Case 1:}

"You shut up! Who do you think you are? I am the teacher and I am in charge, okay! It is not your time to talk!"

The first case highlights a teacher's use of strong language to verbally abuse a student - which obviously displayed lack of regard, respect and consideration for the student.

Case 2:

"I see a piece of paper under your chair, pick it up immediately!"

This case reflects the teacher's power of command when communicating with students. This will only let the students have a social distance with the teacher and thus students may no longer feel free with the teacher. As a consequence, students may have complaints, anger and even develop a hostile attitude towards the teacher.

\section{Case 3:}

"It's okay, go home and have a some rest, everything will be alright." "Never mind, take it easy, you still have a long way to go!

Case 3 displays the general statements that teachers mostly use when a student is faced with a challenge and needs a teacher's help or word of comfort. Despite of the fact that these general statements do not solve practical problems encountered by students, they go a long way in comforting a student no matter what challenge they may be going through. However, teachers should try as much as possible to render practical assistance to needy students. This is the best form of care and is very well appreciated by students, as the saying goes, "actions speak louder than words".

\section{Classification of Teacher-student Communication Barriers}

By means of prepared questionnaire survey and personal interviews, the following classifications of teacher-student communication barriers in the table below were put forward. 


\section{International Journal of Science and Research (IJSR) \\ ISSN (Online): 2319-7064}

Index Copernicus Value (2013): 6.14 | Impact Factor (2015): 6.391

Table 1: Classification of teacher-student communication barrier

\begin{tabular}{|c|c|c|}
\hline $\begin{array}{l}\text { Category/ } \\
\text { Class }\end{array}$ & Typical phrase/discourse & Students Response \\
\hline $\begin{array}{c}\text { Command, } \\
\text { Control }\end{array}$ & $\begin{array}{l}\text { "Why are you always } \\
\text { talking during class? Shut } \\
\text { your mouth up!" }\end{array}$ & $\begin{array}{c}\text { Blame, Anger, } \\
\text { Hostility, Contradict, } \\
\text { Resistance etc. }\end{array}$ \\
\hline $\begin{array}{c}\text { Warning, } \\
\text { Threat }\end{array}$ & $\begin{array}{l}\text { "If you try to bully your } \\
\text { classmates again, I'll not } \\
\text { hesitate to inform your } \\
\text { parents" }\end{array}$ & Fear, Hostility, Yield \\
\hline $\begin{array}{c}\text { Sermons, } \\
\text { Preach }\end{array}$ & $\begin{array}{l}\text { "Cherish the opportunity of } \\
\text { learning in such a } \\
\text { conducive classroom, ah!" }\end{array}$ & Defense, Resistance \\
\hline $\begin{array}{c}\text { Excessive } \\
\text { advice or } \\
\text { suggestions }\end{array}$ & $\begin{array}{c}\text { "When you get the } \\
\text { question paper remember } \\
\text { to scan/browse through the } \\
\text { questions, did you hear } \\
\text { that?" }\end{array}$ & Tremble, Nervous \\
\hline Empty talk & $\begin{array}{l}\text { "Why do you always let } \\
\text { me down?" }\end{array}$ & Helplessness \\
\hline $\begin{array}{l}\text { Force one's } \\
\text { opinions } \\
\text { upon others }\end{array}$ & $\begin{array}{l}\text { "Why didn't you complete } \\
\text { the homework as I } \\
\text { instructed you yesterday?" }\end{array}$ & Defense, Conflict \\
\hline $\begin{array}{l}\text { Arbitrary } \\
\text { criticism }\end{array}$ & "Terrible!" , "Too dull!" & Inferiority, Resistance \\
\hline
\end{tabular}

\section{A Grasp of the Communication Language between Teachers and Students}

The kind of language is usually a direct cause of communication breakdown. The use of the right kind of language plays a very vital role in the transmission of the right kind of information. Language is not only a tool of conveying information, but also a way of expressing feelings and emotions. For the teachers and students to communicate effectively, there is need to understand and employ the teacher-student communication language model.

\subsection{Teacher-student communication language model}

The language model comprises the following modes:

1) Teaching mode

Communication between teachers and students should be in a stable and harmonious mood. For instance, as per statement in case 3 mentioned above, "In such a conducive classroom, you should study hard."

2) Command mode

The Command mode is characterized by authoritarian powers by teachers. The teacher's command words are such that they leave no room for a student to negotiate. The absolute authority bestowed in the teacher leaves a student with no option but to obey the teacher's command without objection or questioning. Use of command words such as "must", "do", "without fail", all fall under this mode.

3) Punishment mode

Punishment mode is essentially a case whereby when a student fails to reach or attain a set goal, the teacher uses phrases of the type; "If not... then...". Such statements show that the student may face serious consequences for not meeting the teacher's expectation.

\subsection{The language skills of teacher-student communication}

For effective communication to take place between teachers and students, there is need to develop some special communication skills. These skills are very imperative, and if ignored can directly adversely affect the effectiveness of the exchange of information between teachers and students. Below are some of the key skills that are very important and needs to be understood by teachers for effective communication.

1) Euphemism

When teachers give negative opinions or suggestions to students, they should do it in a very professional and amicable way with a low tone. This way students feel less tense and also feel greatly respected by the teachers. Refer to the following eight sentences grouped into two sets:

In the first set we have: "I feel so bad!" "I don't feel so good." "I think you are absolutely wrong to say so!" "I don't think this is the right thing to say."

The second set includes: "Don't justify your mistake!" And "Please don't emphasize the excuse!" "Tell me the truth!" "Please tell me the truth!"

These eight simple sentences are often used for correction In the first set of sentences, the first and the third sentence express animosity and are never to be used. Whereas the second and fourth sentence depict a very good example of a clever way of using negative words. For the second set of sentences, the second and the fourth sentences are more reasonable, and represent a smart way to express negativity. As a teacher, it is important to realize that whatever is said to a student will impact that student for the rest of their life. Therefore the words teachers say to students can either build them or bring them down.

\section{2) Implicitness}

For some obvious reason, if the teacher uses an implicit expression to express their view, the information is very clear and therefore communication is effective. Teachers should desist from using ambiguous statements when talking to students or else they will be misunderstood or misquoted. Such communication breakdown can easily be avoided by using simple and clear language whenever a teacher is communicating to students.

3) The proper use of body language

It is said that "facial expression is more than a thousand words." A teacher's eyes represent a strong gesture that conveys a certain expression that may even produce the silence effect on the student. The American Psychologist William James once said: "The most profound principle of human nature is to be appreciated by others". Teachers should always wear a smile, communicate well with students, observe good facial expressions and also give appropriate response to questions directed to them.

\section{Volume 5 Issue 6, June 2016 www.ijsr.net}




\section{International Journal of Science and Research (IJSR) \\ ISSN (Online): 2319-7064}

Index Copernicus Value (2013): 6.14 | Impact Factor (2015): 6.391

\section{The teachers' Moral Cultivation in teacher-student communication}

Teachers' moral cultivation will also affect the effectiveness of teacher-student communication. This can be achieved by teachers' dedication, sense of responsibility, initiative, patience and being careful when communicating to students as this indirectly reflect their behavior. Teachers are role models to the students, so the way they communicate plays a very important role in the lives of students who look up to them. The character of teachers shapes families and societies. The following are some of the key characteristics that teachers are supposed to exhibit for effective communication.

\subsection{Dedication to Work}

Lack of professionalism in some teachers has an big impact on effective communication. Some teachers tend to lack dedication to their work and thus have no desire to communicate properly to students. This factor seriously or adversely affect the communication process. If teachers are dedicated to work, this will inevitably prompt them to focus on their behavior and general conduct in the process of communication thereby positively impacting students.

\subsection{Responsibility}

The teaching profession is not only a form of business, but is also a social responsibility to the teacher which is entrusted to them by students, parents and society at large. The sense of responsibility is not only reflected in the teacher's strictness towards students, but is strongly reflected in the manner in which they maintain and build students' self-esteem and enthusiasm. In trying to uphold this responsibility, teachers are obliged to put in extra effort in communicating well with their students.

\subsection{Initiative}

Whether the teachers work for their own business, or are employed, they need to have a good initiative and persevere Teachers need to put in much effort in their work and must not give up.

\subsubsection{Confidence}

The teacher's self confidence is very cardinal in the process of communication between teachers and students. Once a teacher has enough confidence, they will motivate students or learners and impact their lives forever. Confidence is a very vital ingredient to making people be positive about their lives. A good teacher should prepare well for the lesson so as to have full confidence during lesson delivery, this motivates the students.

\subsubsection{Lack of Satisfaction}

It is believed that where there is no cultivation, there will be no harvest, or in other words, there is no sweet without sweat. Every time a teacher talks with students, he or she expects certain results. This however does not always come out to be the case. As a result some teachers may get disappointed for not achieving what they expected. It is very important to realize that the teacher's hard work is not always proportional to the desired result. Therefore despite these set-downs or set-backs, the teacher is not supposed to give up, they should keep working relentlessly hard. Teachers should therefore be mindful of the constant change in students thought patterns and use the appropriate kind of approach when effecting the communication process with them.

\subsubsection{Perseverance}

The indomitable spirit of perseverance in the process of communication should be embraced by teachers at all times in spite of challenges. It is a known fact that a number of obstacles or barriers to communication between teachers and students will present themselves along the way but it is not an option to give up. Teachers should remain focused and always remember that some of these barriers to effective communication may be due to various individual differences between students. If one method of communication proves futile, it is always wise to change the methodology until effective communication is achieved. This is the spirit of perseverance.

\subsection{Patience and Care}

Patience is a kind of attitude that is not irritable, does not worry nor get tired. Patience is a kind of character that emphasizes on being stable and insisting on despite being in a seemingly unpleasant situation. When handling children who are still going through various of stages of their growth, work may become extremely involving and tedious. Under such circumstances, teachers need to develop the attitude of care and patience. This kind of attitude is very imperative in every aspect of a teachers' life and cannot be ignored.

\subsubsection{Vexatious (Unreasonably troublesome)}

Students' growth process, will at times exhibit some unreasonable behaviors. For example, student A accidentally drops student $\mathbf{B}$ 's pencil box to the ground and it breaks. At this point student A continues to apologize to student $\mathbf{B}$ and even promises to buy a replacement, but it so happens that student $\mathbf{B}$ does not seem to be satisfied. The teacher comes in and tries to comfort the student and try to make him/her understand the situation but the teacher's effort prove futile. The teacher is not supposed to lose patience, instead they should show empathy, taking into account the characteristics of the individual students involved and come up with an amicable psychologically motivated solution.

\subsubsection{Rebellion}

Rebellious behavior in adolescent students is an inevitable reflection of thought pattern as they move in a growth path from a naive to a maturity. Teachers facing students who are passing through this phase are more likely to lose patience because students want to feel independent and want to show off. This is the phase when teachers should be more understanding and exercise patient in handling such 


\section{International Journal of Science and Research (IJSR) \\ ISSN (Online): 2319-7064}

Index Copernicus Value (2013): 6.14 | Impact Factor (2015): 6.391

students.

\subsubsection{Slow in Understanding}

Some students tend to have a weak learning ability. Even when asked on something that has been explained several times, they will still express ignorance. When faced with a student of this kind, a teacher should apply the right kind of methodology to solve this situation rather than resort to furious rage and ranting. The teacher should not use unkind statements when communication to such students even when they exhibit extreme slowness in understanding explained concepts.

\section{How to treat students in communication between teachers and students}

Students are individuals who usually exhibit autonomous behavior. Their behavior in most cases is not in line with the teachers' expectations. Of course, sometimes it may be satisfactory, such as being active with school work, improvement in academic performance etc. However sometimes they may give headache, such as instead of self-studying and doing their work, they will be busy chatting with friends. Teachers need to deal with these cases smoothly by using words of inspiration or praise rather than criticism. The teacher should always adopt the best method of communication with the students so as to achieve the desired goal. The teachers' way of handling students unruly students is of prime importance in the teacher-students communication.

\subsection{Criticism}

As a matter of fact no single person likes to be criticized, the same is true with students. Teachers should not always strongly criticize students when they error or make a mistake. Teachers however can send their criticism with kindness and love, with a low voice. As the saying goes: "The best medicine tastes bitter and an honest advice is usually unpleasant to hear". Therefore, the tone of the criticism of the students is supposed to be appropriate, in the right place and use the right kind of language.

\subsection{Tolerance}

According to the "Encyclopedia Britannica", tolerance is described as the freedom to allow others to be free to act and to judge on situations, and to be patience with people's views that are different from own or traditional views. It is normal for students to make mistakes as such it is imperative to help them understand the error, and improve on it. This will help students in their transition from naivety to maturity. The teacher thus must exercise tolerance or else the negative action is likely to make students feel disgusted. So teachers should be tolerant to students with this weakness and accept them. Tolerance is therefore a very importance quality of a teacher. A teacher who lacks this important quality will have their image and reputation tarnished and students will even lose respect for them.

\subsection{Praise}

Praise is one way of recognizing an individual's effort. Praise can arouse enthusiasm in students and this will make them feel inspired. Enthusiasm and motivation naturally simulate the morale for learning and thereby increase the students' interest. It is thus advisable that a teacher recognizes a students' effort by employing praises. This way students interest in learning will be enhanced thereby effecting the communication process.

\subsubsection{Encouraging praise}

If a certain student scored $50 \%$ during a math test, and the teacher says to the class, "Even if student A only got 50\%, he always works very hard including on weekends, everyone should work as hard as him". Such kind of encouragement will enhance the students' initiative and propel them to work harder.

\subsubsection{Help kind of praise}

When a student scores a low mark, normally there exist some kind of inferiority complex. It is the duty of the teacher to help the student to get out of this complex. This can be done by encouraging them thereby increasing their enthusiasm. This can start from little things as; "The sentence was very well constructed", "The idea of your composition is very clever ", "I like your boldness when you give your contribution in class,". Such statements when said to students will undoubtedly give them morale and naturally propel them to improve on their work, thus gradually slide out of their inferiority.

\subsubsection{Motivation}

Motivation is a very good drive for upward momentum in enhancing the process of communication between teachers and students. There are several kinds of motivation:

The ideal type of motivation

This type of motivation encourages students to work hard and struggle for a noble cause. This is usually achieved by sighting known examples of people who have pulled through similar circumstances.

\section{Confidence- building motivation}

Some students lack self-confidence and feel that whenever they try to do something the results are always pathetic and undesirable. It is the duty of the teachers to use appropriate means of communication to rebuild the confidence in these students. This can be achieved by using motivating statements such as; "You can do it!" "You will surely succeed". These kind of statements enhance students' confidence.

\section{Objective oriented Motivation}

Depending on prevailing circumstances, some teachers will tend to command a destiny for a student. For instance, "Xiao Qing, your score is sports was not impressive, this may affect your final graduation results. The other students are ;likely to get about $90 \%$ whereas you can only get $70 \%$. This difference of 10 marks can adversely affect your 


\section{International Journal of Science and Research (IJSR) \\ ISSN (Online): 2319-7064}

Index Copernicus Value (2013): 6.14 | Impact Factor (2015): 6.391

graduation. You need to give yourself a goal and make some adjustments and improvements". Teachers need to be careful with the way they advise and should try not to command the goal to students.

\section{The ways and means of teacher-student communication}

\subsection{Face to face}

Face to face communication is not only the traditional means of communication, but also the simplest and most direct way. Within a limited period of time, when teachers face students, they find ways and means to seize every opportunity to impress the students with sincerity and honest.

\subsection{Pen Communication}

In the teachers day to day work, it is possible to reach the hearts of their students using a pen, hence effecting heart to heart communication.

\subsubsection{Weekly diary}

A weekly diary is a proven effective way to stimulate student-teacher communication. This is done by asking students to write down or recite some of the activities or experiences encountered during the course of the week and then asking them to come and narrate to the class. This simple methodology will help unveil unexpectedly rich information from students and amazing results.

\subsubsection{Comments}

Teachers can at times write comments and sentiments to students as a means of exchanging and conveying feelings with them. Good comments in language form are an effective means of enhancing students' performance and confidence.

\subsubsection{Greeting cards and Birthday cards}

Whenever a student celebrated their birthday, a famous teacher called Huang Jia-can could write a very heart-touching Birthday card. Such gestures tend to narrow the gap that has long existed between students and teachers.

\subsection{Action oriented Communication}

The teachers' words, actions and deeds can attract the attention of students. In lighter cases, a teacher may help style up a student's hair, or even put in position a student's attire. Such seemingly small gestures can move the hearts of young students.

\subsection{Online communication}

This involves use of social networking platforms such as AOL, ICQ, IRC, Skype, MSN, QQ, Wechat, Snap Chat, and many others in common use today. This reduces the gap between the students and teachers. As such when there is a certain degree of closeness between teachers and students, it is easy for a student to approach the teacher for help when faced with any challenge.

\section{Conclusion}

Harmonious teacher-student relationship is a prerequisite for smooth carrying out of teaching or educational activities There is need to establish a good relationship between teachers and students by establishing an emotional as well as harmonious communication link based on mutual acceptance and understanding. Effective communication between teachers and students will help in expressing love, assistance and also show consideration for each other. This way students will be more willing to accept their teachers and the views thereof. The effective communication between teachers and students is the golden key to opening the window of the students' mind, and it is an effective strategy to promote success of educational policies and other curricular activities.

\section{References}

[1] Rock J, “ Educational comics [M]”, Educational Science Press, 1999.

[2] Guo M, "The great love of teachers - the witness of the miracle of education [M]", University of Electronic Science and Technology Press, 2010.

[3] Patriotic Eloquent Music Teacher [M], Beijing Ocean Press, 2002.

[4] Zhuang J, Li Z, "Teachers' body language art [M]" Shandong Education Press, 1993. [Chinese edition]

[5] Zhu Y, "Into the most ideal education [M]" Li River.2007 years. [Chinese edition]

[6] Feng J, "Basic principles of education", Higher Education Press [M], 2003. [Chinese edition]

[7] $\mathrm{Ni} \mathrm{C}$, "The establishment of a new type of teacher-student relationship to improve the quality of teaching $[\mathrm{J}]$ ", Vocational and Technical, 2011 (8). [Chinese edition]

[8] Wang D, "Editor in Chief of Wang Hanlan Education [M], People's Education Press.1989. [Chinese edition]

[9] Sue H, Linsky Du Diankun, "Compiler - To the teacher's advice [M]”, Educational Science Press, 1984. [Chinese edition]

[10] Zhenghua Zhang. Establishment of high precision and constant temperature environment electrochemical heat system [D] Changsha: Central South University, 2008

\section{Author Profile}

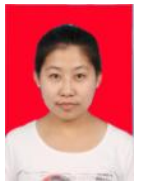

JU Quan-juan. Department of Vocational Education, Tianjin University of Technology and Education,Tianjin 300222, P.R. China. Current position, grads: postgraduate at Tianjin University of Technology and Education. 